\title{
Enhanced surveillance for acute and likely acute hepatitis B in Canada: 1999 to 2002
}

\author{
David Boulos $\mathrm{MSc}^{1}$, Neil J Goedhuis BSc${ }^{1}$, Jun Wu MD PhD ${ }^{1}$, Beverley Baptiste RN BScN², \\ Darlene Poliquin $\mathrm{RN} B S c N^{3}$, Janet Furseth $\mathrm{RN} \mathrm{BN}{ }^{4}$, Jessica Ip Chan ${ }^{5}$, Grlica Bolesnikov $\mathrm{MD}^{6}$, \\ Faye Barichello ${ }^{7}$, Anton Andonov MD PhD ${ }^{8}$, Antonio Giulivi MD FRCPC ${ }^{1}$
}

D Boulos, NJ Goedhuis, J Wu, et al. Enhanced surveillance for acute and likely acute hepatitis B in Canada: 1999 to 2002. Can J Infect Dis Med Microbiol 2005;16(5):275-281.

OBJECTIVE: To assess the incidence of clinically identified hepatitis B cases, as well as the demographic and risk behaviour profiles of these cases in a defined Canadian population.

METHODS: An enhanced hepatitis surveillance system was established in October 1998 to identify acute hepatitis B and C cases in Canada. Acute and likely acute cases, as determined by laboratory testing, collectively defined incident clinical hepatitis B cases. Data from 1999 to 2002 on incidence, demographic characteristics and risk behaviour characteristics were collected and analyzed.

RESULTS: During the 1999 to 2002 surveillance period, 379 cases were identified in a target population ranging from 3,128,179 to $8,576,071$ individuals. The observed hepatitis B incidence rate was $1.93 / 100,000$ person-years in the surveillance area. The incidence rate was 2.74 times higher in men. The observed incidence rates decreased for all age groups over the surveillance period but remained high in the 20- to 29-year-old and 30- to 39-year-old age groups, as well as in men. Of the incident cases, $55.9 \%$ self-identified as being born in Canada and $18.5 \%$ as being born in Asia, while $18.7 \%$ did not identify a birth area. Of the Canadian-born cases, $61.3 \%$ identified themselves as Caucasian, $11.3 \%$ as Aboriginal and $23.6 \%$ as no ethnic category. Injection drug use was the most reported risk behaviour (19.1\%), followed closely by sex-associated risk behaviours. A large proportion, $24 \%$, indicated none of the known risk behaviours. CONCLUSIONS: The hepatitis B incidence rate has shown some decrease in the surveillance population from 1999 to 2002 and this may be due, in part, to past intervention programs (eg, vaccination programs and health promotion campaigns). The authors' results identify some high-risk groups that would benefit from additional prevention and control programs, and further targeted research and intervention.

Key Words: Canada; Hepatitis B; Incidence; Risk factors; Surveillance

\section{Surveillance accrue de l'hépatite $B$ aiguë et pro- bablement aiguë au Canada, entre 1999 et 2002}

BUT : Évaluer l'incidence des cas d'hépatite B cliniquement reconnus, ainsi que l'influence du portrait démographique et des comportements à risque sur la fréquence de la maladie dans une population donnée au Canada.

MÉTHODE : Un système amélioré de surveillance de l'hépatite a été mis sur pied en octobre 1998 pour faciliter la reconnaissance des cas d'hépatite $\mathrm{B}$ ou d'hépatite $\mathrm{C}$ aiguë. Les cas d'hépatite aiguë et probablement aiguë, d'après les examens de laboratoire, ont formé dans l'ensemble les nouveaux cas cliniques d'hépatite B. Des données sur l'incidence de la maladie, le portrait démographique et les caractéristiques des comportements à risque ont été recueillies entre 1999 et 2002, puis analysées.

RÉSULTATS : Au cours de la période de surveillance qui s'est écoulée entre 1999 et 2002, 379 cas ont été cernés dans une population cible variant de 3128179 à 8576071 personnes. Le taux d'incidence de l'hépatite B s'est établi à 1,93/100 000 personnes-années dans la zone de surveillance. Le taux d'incidence était 2,74 fois plus élevé chez les hommes. Les taux d'incidence enregistrés ont diminué dans tous les groupes d'âge durant la période de surveillance, mais ils sont restés tout de même élevés dans les tranches d'âge de 20 à 29 ans et de 30 à 39 ans, de même que chez les hommes. Par ailleurs, 55,9 \% des nouveaux patients se sont déclarés canadiens de naissance; $18,5 \%$, d'origine asiatique, et $18,7 \%$ n'ont précisé aucune origine. Parmi les Canadiens de naissance autodéclarés, $61,3 \%$ étaient de race blanche; $11,3 \%$, des Autochtones, et 23,6 \% n'ont indiqué aucun groupe ethnique. L'utilisation de drogues injectable était le comportement à risque le plus fréquent (19,1\%), suivi des comportements à risque liés au sexe. Une bonne proportion de répondants $(24 \%)$ n'ont indiqué aucun des comportements à risque connus.

CONCLUSIONS : Le taux d'incidence de l'hépatite B a diminué quelque peu dans la population à l'étude entre 1999 et 2002 et cela peut s'expliquer en partie par les programmes d'intervention antérieurs (ex. : programmes de vaccination, campagnes de promotion de la santé). Les auteurs de l'étude ont toutefois ciblé quelques groupes particulièrement exposés, qui profiteraient de programmes supplémentaires de prévention et de lutte contre la maladie, et relevé des domaines particuliers de recherche et d'intervention.

${ }^{1}$ Bloodborne Pathogens Section, Centre for Infectious Disease Prevention and Control, Health Canada, Ottawa, Ontario; ${ }^{2}$ Capital Health, Edmonton, Alberta; ${ }^{3}$ Public Health and Long Term Care Branch, City of Ottawa, Ottawa, Ontario; ${ }^{4}$ Calgary Health Region, Calgary Alberta; ${ }^{5}$ Vancouver Coastal Health, Vancouver, British Columbia; ${ }^{6}$ Department of Health and Wellness, Fredericton, New Brunswick; ${ }^{7}$ BC Hepatitis Services, BC Centre for Disease Control, Vancouver, British Columbia; ${ }^{8}$ National Microbiology Laboratory, Canadian Science Centre for Human and Animal Health, Health Canada, Winnipeg, Manitoba

Correspondence: Mr David Boulos, Immunization and Respiratory Infections Division, Centre for Infectious Disease Prevention and Control, Public Health Agency of Canada, AL 0602C, Building 6, Tunney's Pasture, Ottawa, Ontario K1A OL2. Telephone 613-954-8501,

fax 613-957-2842, e-mail david_boulos@phac-aspc.gc.ca

Received for publication August 11, 2004. Accepted March 19, 2005 
$\mathrm{H}$ epatitis B virus (HBV) infections represent an important illness burden among Canadians. The prevalence of hepatitis B varies among population subgroups across Canada. In 1997, it was suggested that the prevalence of hepatitis B in the general population was well over 100,000 (1). It was further indicated in 1999 that the prevalence of hepatitis B was approximately $4 \%$ in the Aboriginal population, $4.3 \%$ in the immigrant population and $0.2 \%$ to $0.5 \%$ in the nonimmigrant, non-Aboriginal population (2). This equates to a range of 206,000 to 280,000 infected people in the general population. In a recent study of an Aboriginal community in Manitoba, serological evidence of past HBV infection was reported in $2.2 \%$ of the sample population (3). HBV can cause acute and chronic infection. An acute HBV infection is a new infection that can range from subclinical disease to fulminant hepatic failure. Acute HBV infections can resolve without any sequelae; however, some infections do not resolve, instead progressing to chronic infection. The likelihood of becoming chronically infected varies with age and is more likely in neonates and children than in adults.

Individuals with an $\mathrm{HBV}$ infection can carry the virus in their blood, as well as in body fluids such as semen, vaginal secretions and saliva (4). HBV in blood and semen can be present in sufficient quantity to allow transmission $(4,5)$, while vaginal secretions and saliva are considered less efficient as modes of transmission $(5,6)$. An HBV infection can result when a noninfected person's mucous membranes or broken skin comes into contact with infective material (eg, through the use of infected needles) (7). The predominant known risk factors associated with HBV transmission in Canada are sexual contact and injection drug use (IDU) when these behaviours involve contact with an infected individual's blood and/or body fluids $(1,4,8,9)$.

HBV infections are nationally reportable in Canada through the Notifiable Disease Reporting System (NDRS) (10) and have been reportable in Canada since 1969 (8). In 1999, the incidence rate for hepatitis B reported by the NDRS was 4.19 per 100,000 persons (10). The usefulness of the data obtained through this routine national surveillance is limited by a number of factors. Provinces and territories vary in terms of reporting practices, with some reporting case-by-case data and others reporting only aggregate data stratified by age and sex. Furthermore, risk factor information is not collected by this system. To overcome some of the reporting limitations associated with the NDRS, an enhanced sentinel surveillance system for hepatitis B and C was established in late 1998. The system is now known as the Enhanced Hepatitis Strain Surveillance System.

The objective of the present report was to update the information provided in an earlier report (8) on the enhanced sentinel surveillance system. The system captures information on acute and chronic newly identified infections in the sites under surveillance. Demographic information and involvement in possible risk behaviours for transmission are also obtained from the identified cases of hepatitis B.

\section{METHODS}

The methods for the present article have been described in a previous report (8), with some modifications as necessary.

\section{Population}

The enhanced surveillance began on October 1, 1998, with the Ottawa-Carleton Health Department in Ottawa, Ontario, and the
Capital Health Region in Edmonton, Alberta. The Calgary Regional Health Authority in Calgary, Alberta, and the Winnipeg Regional Health Authority in Winnipeg, Manitoba, joined the project on January 1, 1999. In 2000, the Vancouver Coastal Health Authority in Vancouver, British Columbia, and the Department of Health and Wellness of New Brunswick became participants on April 1 and August 1, respectively. Both the Capital District Health Authority in Halifax, Nova Scotia, and the British Columbia Centre for Disease Control in Vancouver, British Columbia, joined the project on April 1, 2002. The present report is an analysis of the cumulative data submitted from 1999 to 2002 as of May 31, 2003.

Population numbers were provided by the participating sites. The population covered by this surveillance was estimated to be $3,128,179$ in $1999,4,701,955$ in 2000, 4,724,246 in 2001 and $8,576,071$ in 2002. Using the 2001 Canadian census number of $30,007,094$, this represents a population coverage that increased from $10.4 \%$ in 1999 to $28.6 \%$ in 2002 . These population numbers and their associated age and sex breakdowns were used to compute rates; however, in 2000 and 2002, new sites began participation partway into the surveillance year and, assuming a constant rate throughout the year, person-year rates were adjusted proportionately for these new sites (see section entitled 'Data analysis').

\section{Case definition}

The case definition was based on clinical and laboratory findings. The clinical criteria included an acute illness with the discrete onset of symptoms associated with hepatitis (ie, nausea, malaise, fatigue, dark urine, loss of appetite and jaundice) and elevated serum aminotransferase levels. The laboratory criteria for acute hepatitis B included serum aminotransferase levels that were at least 2.5 times the upper limit of normal, a negative hepatitis A immunoglobulin (Ig) M antibody test (a positive test would indicate a possible $\mathrm{A}$ and $\mathrm{B}$ mixed infection), and either a positive hepatitis B surface antigen ( $\mathrm{HBs} \mathrm{Ag}$ ) test or a positive result for the IgM antibody to the hepatitis B core antigen ( $\operatorname{lgM}$ anti-HBc). Alternatively, a seroconversion on either the HBsAg test or the IgM anti-HBc test within 12 months was considered sufficient laboratory criteria for acute hepatitis B.

Chronic hepatitis B cases were defined to include subjects who did not fully meet the previously stated criteria for an acute categorization but had sufficient laboratory evidence to indicate infection, such as a positive HBsAg test that persisted for longer than six months.

Indeterminate hepatitis B cases were defined to include individuals whose collected information was insufficient to categorize their status as acute or chronic. However, indeterminate hepatitis B cases were reclassified to a likely acute status if they tested positive for IgM anti-HBc, regardless of the presence of clinical symptoms and elevated aminotransferase. When summarizing results, acute and likely acute cases were together treated as incident cases.

When a subject was determined to be an acute or chronic hepatitis B case, the date of identification was determined using the laboratory test dates. The date of identification for a hepatitis B case was the date of the first positive $\mathrm{HBsAg}$ test or IgM anti-HBc test.

\section{Operating procedure}

A consensus protocol and standardized case definitions were developed and used by all participants in the enhanced surveillance project. At least one investigator was assigned by each site to participate in this surveillance. The participating sites informed 
all physicians and private and public health laboratories in their jurisdiction of this enhanced surveillance.

Laboratories provided test results and other information on the newly identified hepatitis B cases to the site investigators. These data were reported either automatically or by site investigators who contacted the laboratories for information on at least a weekly basis. Physicians were asked to perform follow-up tests for hepatitis at least three months after symptom onset for individuals who were not diagnosed with hepatitis A, B or C but were symptomatic. Site investigators contacted physicians of newly identified hepatitis B cases for information on clinical symptoms and laboratory test results.

The site investigators attempted to interview all newly identified hepatitis B cases (except for those remotely acquired hepatitis B cases who were first-generation immigrants from a high endemic area, such as Southeast Asia and Africa) to collect epidemiological and demographic data, and to confirm any changes to other items. Some participating sites were required by provincial legislation or regulation to obtain informed consent before sharing any depersonalized information with Health Canada, and in these instances, informed consent was sought before any case interview began. Patients were informed as to how their information would be used by Health Canada, and consent for the sharing of these data was sought.

\section{Data collection}

Data elements were collected on patient demographics, clinical characteristics, laboratory tests and potential hepatitis B transmission risk factors. Data entry into an electronic database was coordinated by investigators at the participating sites; these data were depersonalized before being sent to the Blood Safety Surveillance and Health Care Acquired Infections Division within the Centre for Infectious Disease Prevention and Control at the Public Health Agency of Canada. Efforts were made by site investigators and by those at the Public Health Agency of Canada to check for accuracy and completeness of the data and to eliminate duplicate entries.

The potential acute hepatitis B transmission risk factors relate to behaviours or exposures over the six-month period before the infection. Hepatitis B cases tend to have many risk factors. The collected risk factors were ranked using a combination of transmission efficiency, importance and other considerations to produce a mutually exclusive risk behaviour categorization (this has been discussed in an earlier publication [8]); acute cases were assigned to a single risk behaviour category if a history of such a risk behaviour was reported in the six months before disease onset, regardless of reporting a history of lower-ranked risk behaviours. In descending order, the mutually exclusive ranking of potential risk factors for acute hepatitis B infection was as follows: IDU; nonIDU; blood transfusion; receipt of blood products (ie, albumin, immune globulin, clotting factor); two or more heterosexual partners; homosexual activity in men; sexual contact with an HBV carrier; tattooing; body piercing; acupuncture; occupational exposure to blood or body fluids; hemodialysis; HBV infection in one's household; an association with an institution for the developmentally delayed (institution-associated); history of hospitalization; surgery; receipt of a tissue or organ transplant; dental visits; and incarceration.

\section{Data analysis}

Because some sites participating in the surveillance initiated their participation in different years, three cohorts were
TABLE 1

Observed frequencies and rates (per 100,000 personyears) of hepatitis $B$ reported by sites involved in the surveillance over the 1999 to 2002 study period*

\begin{tabular}{lccc}
\hline & \multicolumn{3}{c}{ Hepatitis B } \\
\cline { 2 - 4 } Sex & Acute/likely acute $^{\dagger}$ & Chronic & Indeterminate \\
\hline Women & $79 / 25(1.04)$ & $2796(31.76)$ & $56(0.56)$ \\
Men & $231 / 44(2.85)$ & $3412(40.12)$ & $80(0.83)$ \\
Both & $310 / 69(1.93)$ & $6208(35.87)$ & $136(0.69)$ \\
\hline
\end{tabular}

${ }^{*}$ Rates are reported in parentheses; ${ }^{\dagger}$ Rates reported in parentheses are for acute and likely acute combined

defined based on year of initiation. The four sites that joined the surveillance project in 1999 represented cohort 1, the two sites that joined in 2000 represented cohort 2 and the additional two sites that joined in 2002 represented cohort 3. Rates for sites that initiated participation after January 1 of a given year were computed using population numbers that were factored according to the proportion of the year that surveillance was implemented.

Data processing and analysis were largely implemented using SAS/STAT software (SAS Institute Inc, USA) (11).

In comparing rates, a Poisson regression was used to model the effects of year, cohort, age, sex and their two-way interactions. The Poisson regression assumptions of independence in the occurrence of identified cases and the relatively low rate of case occurrence were felt to be sufficiently satisfied. As described earlier, the collected data were provided by health regions involved in the project, and a cohort variable was identified by the year each health region became part of the project from 1999 to 2002. If the cohort variable was determined to be not statistically significant $(P>0.05)$, then the analysis of year, age and sex was to be recomputed and the effect of these variables reassessed with all cohorts treated as one. Likelihood ratio statistics (SAS type 3) were initially used to assess the significance of each variable or interaction term in the model, and when significant, the relative rates for the levels of these significant terms were assessed using confidence intervals.

In comparing proportions, a Z-test for proportions was applied with the assumption that samples were sufficiently large for a normal distribution to apply.

\section{Observed incidence}

\section{RESULTS}

During the 1999 to 2002 surveillance period, 310 subjects were reported to have an acute HBV infection based on the case definition, and 69 additional subjects were defined as having a likely acute HBV infection. Taken together, this corresponds to a rate of 1.93 per 100,000 person-years (Table 1 ). The rate of acute and likely acute infection in men was 2.74 times higher than in women. The identification rate for chronic HBV infection was 35.87 per 100,000 person-years and the rate was 1.26 times higher in men than in women. The identification rate for an indeterminate $\mathrm{HBV}$ infection over the study period was 0.69 per 100,000 person-years and the rate was 1.48 times higher in men than in women.

\section{Cohort comparison and demographics}

Poisson regressions that included year, age and sex variables were used to compare the acute and likely acute rate between cohorts to assess whether the data could be merged for a given 
TABLE 2

Observed age- and sex-specific frequencies and rates (per 100,000 person-years) of acute and likely acute cases of hepatitis B that were reported by sites involved in the surveillance over the 1999 to 2002 study period* $^{\star}$

\begin{tabular}{|c|c|c|c|c|c|c|c|c|}
\hline \multirow[b]{2}{*}{ Age (years) } & \multicolumn{2}{|c|}{1999} & \multicolumn{2}{|c|}{2000} & \multicolumn{2}{|c|}{2001} & \multicolumn{2}{|c|}{2002} \\
\hline & Women & Men & Women & Men & Women & Men & Women & Men \\
\hline$<5$ & $0(0.00)$ & $0(0.00)$ & $0(0.00)$ & $1(0.81)$ & $0(0.00)$ & $0(0.00)$ & $0(0.00)$ & $1(0.48)$ \\
\hline $5-9$ & $0(0.00)$ & $0(0.00)$ & $0(0.00)$ & $0(0.00)$ & $0(0.00)$ & $0(0.00)$ & $1(0.44)$ & $0(0.00)$ \\
\hline $10-19$ & $3(1.48)$ & $2(0.94)$ & $3(1.17)$ & $1(0.37)$ & $1(0.33)$ & $4(1.28)$ & $2(0.40)$ & $1(0.19)$ \\
\hline 20-29 & $6(2.67)$ & $10(4.47)$ & $5(1.67)$ & $22(7.41)$ & $6(1.74)$ & $20(5.84)$ & $11(2.09)$ & 18 (3.39) \\
\hline 30-39 & $12(4.33)$ & $25(9.05)$ & 7 (1.99) & $28(7.91)$ & $6(1.51)$ & $22(5.74)$ & $8(1.30)$ & $24(4.08)$ \\
\hline $40-59$ & $6(1.42)$ & $14(3.34)$ & $6(1.05)$ & $19(3.34)$ & $8(1.19)$ & $18(2.70)$ & $7(0.62)$ & $34(3.02)$ \\
\hline$\geq 60$ & $2(0.78)$ & $2(1.02)$ & $2(0.59)$ & $2(0.76)$ & $1(0.25)$ & $4(1.28)$ & $1(0.14)$ & $3(0.53)$ \\
\hline All ages & $29(1.83)$ & $53(3.44)$ & $23(1.11)$ & $73(3.63)$ & $22(0.92)$ & $68(2.96)$ & $30(0.76)$ & $81(2.14)$ \\
\hline
\end{tabular}

${ }^{*}$ Rates are reported in parentheses

TABLE 3

Areas of birth of acute and likely acute cases of hepatitis B reported by sites involved in the surveillance over the 1999 to 2002 study period

\begin{tabular}{lccc}
\hline & \multicolumn{2}{c}{ Acute and likely acute hepatitis B cases } \\
\cline { 2 - 4 } Area of birth & $\begin{array}{c}\text { Women } \\
\text { (n [\%]) }\end{array}$ & $\begin{array}{c}\text { Men } \\
\text { (n [\%]) }\end{array}$ & $\begin{array}{c}\text { Both sexes } \\
\text { (n [\%]) }\end{array}$ \\
\hline Africa & $3(2.9)$ & $7(2.5)$ & $10(2.6)$ \\
Asia & $20(19.2)$ & $50(18.2)$ & $70(18.5)$ \\
Canada & $63(60.6)$ & $149(54.2)$ & $212(55.9)$ \\
United States & $3(2.9)$ & $0(0)$ & $3(0.8)$ \\
Central America & $2(1.9)$ & $6(2.2)$ & $8(2.1)$ \\
South America & $0(0)$ & $1(0.4)$ & $1(0.3)$ \\
Europe & $1(1.0)$ & $3(1.1)$ & $4(1.1)$ \\
Australasia & $0(0)$ & $0(0)$ & $0(0)$ \\
Unknown & $12(11.5)$ & $59(21.5)$ & $71(18.7)$ \\
Total number of & 104 & 275 & 379 \\
$\quad$ individuals & & & \\
\hline
\end{tabular}

year. Comparisons between cohorts 1 and 2 indicated that over the 2000 to 2002 period, cohort 2 had rates that were 1.18 times higher than cohort 1 , but this relative rate was not statistically significant given that the other variables were in the Poisson model (likelihood ratio $=1.52$, degree of freedom $[\mathrm{df}]=1, \mathrm{P}=0.2179$ ). Comparisons among cohorts 1,2 and 3 indicated that during 2002, cohort 1 had a rate that was 1.12 times higher than that of cohort 3 , and cohort 2 had a rate that was 1.13 times higher than that of cohort 3 , but the differences due to cohort were not statistically significant given that the other variables were in the Poisson model (likelihood ratio = 0.34, $\mathrm{df}=2, \mathrm{P}=0.8443)$. Because the cohort differences were not statistically significant, the cohort data were combined per year.

The observed acute and likely acute hepatitis B rates for all cohorts combined are reported in Table 2 for each surveillance year. A Poisson regression was used to assess age, sex, surveillance year and their two-way interactions. All two-way interactions were determined to be not statistically significant. The year (likelihood ratio $=18.63, \mathrm{df}=3, \mathrm{P}=0.0003$ ), age (likelihood ratio $=213.17, \mathrm{df}=4, \mathrm{P}<0.0001$ ) and sex (likelihood ratio $=83.36, \mathrm{df}=1, \mathrm{P}<0.0001)$ main effect variables were each determined to have a statistically significant effect on the acute hepatitis B rates. The observed rates decreased for all ages over the surveillance period from 1999 to 2002 but remained high in the 20- to 29-year-old and 30- to 39-year-old age groups, as well as in men. Relative to the 1999 surveillance year, and controlling for the effects of age and sex, the acute and likely acute rate for 2000 was lower, but this difference was not statistically significant (relative rate $=0.89 ; 95 \%$ CI 0.66 to 1.20), while the acute rates for 2001 and 2002 were both lower and statistically significant, with relative rates of 0.73 (95\% CI 0.54 to 0.99 ) and 0.57 (95\% CI 0.43 to 0.75$)$, respectively. Relative to individuals younger than 20 years of age, and controlling for the effects of sex and year, individuals in the 20- to 29-year-old, 30- to 39-year-old and 40- to 59-year-old age groups each had higher acute and likely acute hepatitis B rates that were statistically significant. The 20- to 29-year-old age group had a relative rate of 8.81 (95\% CI 5.44 to 14.24 ), the 30 - to 39-year-old age group had a relative rate of 10.18 (95\% CI 6.36 to 16.29 ), the 40 - to 59 -year-old age group had a relative rate of 5.09 (95\% CI 3.16 to 8.20 ) and the individuals who were 60 years of age or older had a relative rate of 1.51 (95\% CI 0.79 to 2.89). After controlling for the effects of year and age, the rate of acute hepatitis B infection was 2.69 times higher in men than in women (95\% CI 2.15 to 3.38) and this relative rate was statistically significant.

The areas of birth reported for the acute and likely acute hepatitis B cases are presented in Table 3. The majority of cases (55.9\%) were born in Canada, and $18.5 \%$ were born in Asia. However, there were a high proportion of cases $(18.7 \%)$ whose area of birth was listed as unknown. Generally, the proportion from each area of birth was similar for men and women. However, the proportion of women born in the United States was greater than that of men $(Z=2.833, P=0.0047)$, while the proportion of men in the unknown category was greater than that of women $(Z=2.208, P=0.0273)$; both of these differences were statistically significant.

The primary self-identified ethnic groups of acute and likely acute cases who were born in Canada are summarized in Table 4, along with cases whose area of birth was unknown. The majority of Canadian-born cases (61.3\%) were of Caucasian ethnicity, while $23.6 \%$ were of unknown ethnicity and $11.3 \%$ were of Aboriginal ethnicity. There were some differences between men and women. Among the Canadian-born cases, the proportion of women with an Aboriginal ethnicity was greater than that of men $(Z=3.257, P=0.0011)$, while the proportion of men of Caucasian ethnicity was greater than that of women $(Z=2.355, P=0.0185)$; both of these differences were statistically significant. Similar comparisons were conducted for cases that were either born in Canada or whose birth area was unknown. Within this combined subgroup, only the 
TABLE 4

Self-identified primary ethnic groups of acute and likely acute cases of hepatitis B that were indicated as born in Canada or having an unknown country of birth reported by sites involved in the surveillance over the 1999 to 2002 study period

\begin{tabular}{|c|c|c|c|c|c|c|}
\hline \multirow[b]{2}{*}{ Primary ethnic group } & \multicolumn{3}{|c|}{$\begin{array}{l}\text { Acute and likely acute hepatitis B } \\
\text { (indicated born in Canada) }\end{array}$} & \multicolumn{3}{|c|}{$\begin{array}{c}\text { Acute and likely acute hepatitis B } \\
\text { (indicated born in Canada or unknown) }\end{array}$} \\
\hline & Women (n [\%]) & Men (n [\%]) & Both (n [\%]) & Women (n [\%]) & Men (n [\%]) & Both (n [\%]) \\
\hline Aboriginal & $14(22.2)$ & $10(6.7)$ & $24(11.3)$ & $14(18.7)$ & $10(4.8)$ & $24(8.5)$ \\
\hline Black & $0(0)$ & $2(1.3)$ & $2(0.9)$ & $0(0)$ & $2(1.0)$ & $2(0.7)$ \\
\hline Asian & $3(4.8)$ & $3(2.0)$ & $6(2.8)$ & $3(4.0)$ & $4(1.9)$ & $7(2.5)$ \\
\hline Caucasian & $31(49.2)$ & $99(66.4)$ & $130(61.3)$ & $32(42.7)$ & $109(52.4)$ & $141(49.8)$ \\
\hline Unknown & $15(23.8)$ & $35(23.5)$ & $50(23.6)$ & $26(34.7)$ & $83(39.9)$ & $109(38.5)$ \\
\hline Total number of individuals & 63 & 149 & 212 & 75 & 208 & 283 \\
\hline
\end{tabular}

proportion of women who were of Aboriginal ethnicity was greater relative to men $(\mathrm{Z}=3.693, \mathrm{P}=0.0002)$, and this difference was statistically significant.

\section{Risk behaviours}

The profile for the $64.9 \%(n=246)$ of acute and likely acute hepatitis B cases that were interviewed on their risk behaviours is in contrast with the $35.1 \%(n=133)$ of cases that were not able to be interviewed. The only statistically significant differences between the interviewed and noninterviewed cases related to area of birth. There were more interviewed cases from Canada $(65.9 \%)$ than there were noninterviewed cases $(37.6 \%)$, and this difference was statistically significant $(\mathrm{Z}=5.288, \mathrm{P}<0.0001)$. Additionally, there were more noninterviewed cases that had an unknown area of birth $(36.8 \%)$ than there were interviewed cases $(8.9 \%)$, and this difference was also statistically significant $(\mathrm{Z}=6.644, \mathrm{P}<0.0001)$.

The risk behaviours reported by interviewed cases, categorized using the mutually exclusive categorization and summarized across sex (Table 5) and age (Table 6), indicated that IDU was the most reported risk behaviour at $19.1 \%$, followed closely by sex-associated risk behaviours (ie, two or more heterosexual partners) at $17.9 \%$, male homosexual activity at $11.0 \%$ and sexual contact with an HBV carrier at $6.9 \%$. However, there was a large proportion, 24\%, who indicated none of the known risk behaviours.

The reported risk behaviours differed only slightly between men and women (Table 5). However, there was a statistically significant difference associated with reported sexual risk behaviours. The female cases reported a higher proportion of heterosexual activity with two or more partners than did men ( $28.3 \%$ versus $14.5 \%$, respectively), and this difference was statistically significant $(\mathrm{Z}=2.428, \mathrm{P}=0.01517)$.

The risk behaviours reported by interviewed cases, also categorized using the mutually exclusive categorization, differed slightly by age group (Table 6). Pairwise comparisons made between the reported risk behaviours for each age grouping and the 20- to 29-year-old age group indicated that there were statistically significant differences between the 40- to 59-year-old and 20 - to 29-year-old age groups, and between the 60 years and older and 20- to 29-year-old age groups. Sexual contact with an HBV carrier was reported less with statistical significance $(\mathrm{Z}=2.70, \mathrm{P}=0.0069)$ in the 40 - to 59 -year-old age group at $2.7 \%$, compared with $15.8 \%$ in the 20 - to 29 -year-old age group, while non-IDU was reported less with a marginal statistical significance $(Z=1.87, \mathrm{P}=0.0609)$ in the 40 - to 59-year-old age group at $2.7 \%$, compared with $10.5 \%$ in the 20 - to 29 -year-old age group.

\section{TABLE 5}

Risk behaviours of interviewed acute and likely acute cases of hepatitis B, categorized using a mutually exclusive risk behaviour scheme and summarized by sex, reported by sites involved in the surveillance over the 1999 to 2002 study period

\begin{tabular}{lccc}
\hline & \multicolumn{3}{l}{ Acute and likely acute hepatitis B } \\
\cline { 2 - 4 } Risk factor & $\begin{array}{c}\text { Women } \\
\text { (n [\%]) }\end{array}$ & $\begin{array}{c}\text { Men } \\
\text { (n [\%]) }\end{array}$ & $\begin{array}{c}\text { Both } \\
\text { (n [\%]) }\end{array}$ \\
\hline Injection drug use & $12(20.0)$ & $35(18.8)$ & $47(19.1)$ \\
Noninjection drug use & $5(8.3)$ & $13(7.0)$ & $18(7.3)$ \\
Blood transfusion & $0(0.0)$ & $1(0.5)$ & $1(0.4)$ \\
Receipt of blood product & $1(1.7)$ & $1(0.5)$ & $2(0.8)$ \\
Heterosexual, two or more partners & $17(28.3)$ & $27(14.5)$ & $44(17.9)$ \\
Male homosexual activity & $0(0.0)$ & $27(14.5)$ & $27(11.0)^{*}$ \\
Sexual contact with an HBV carrier & $5(8.3)$ & $12(6.5)$ & $17(6.9)$ \\
Tattooing & $0(0.0)$ & $0(0.0)$ & $0(0.0)$ \\
Body piercing & $0(0.0)$ & $0(0.0)$ & $0(0.0)$ \\
Acupuncture & $2(3.3)$ & $3(1.6)$ & $5(2.0)$ \\
Occupational blood contact & $0(0.0)$ & $1(0.5)$ & $1(0.4)$ \\
Hemodialysis & $0(0.0)$ & $0(0.0)$ & $0(0.0)$ \\
HBV carrier in household & $2(3.3)$ & $4(2.2)$ & $6(2.4)$ \\
Institution-associated & $0(0.0)$ & $1(0.5)$ & $1(0.4)$ \\
Hospitalization & $3(5.0)$ & $4(2.2)$ & $7(2.8)$ \\
Surgery & $1(1.7)$ & $1(0.5)$ & $2(0.8)$ \\
Tissue/organ transplant recipient & $0(0.0)$ & $0(0.0)$ & $0(0.0)$ \\
Dental visit & $1(1.7)$ & $7(3.8)$ & $8(3.3)$ \\
Incarceration & $0(0.0)$ & $0(0.0)$ & $0(0.0)$ \\
Unknown & $11(18.3)$ & $49(26.3)$ & $60(24.4)$ \\
Interviewed & $60(57.7)$ & $186(67.6)$ & $246(64.9)$ \\
Not interviewed & $44(42.3)$ & $89(32.4)$ & $133(35.1)$ \\
Total & 104 & 275 & 379 \\
\hline
\end{tabular}

*This risk factor is identified as the most likely route of transmission by $11.0 \%$ of interviewed cases and, more specifically, $14.5 \%$ of the interviewed male cases. HBV Hepatitis B virus

The blood transfusion $(\mathrm{Z}=2.41, \mathrm{P}=0.01615)$, blood product $(\mathrm{Z}=2.41, \mathrm{P}=0.01615)$ and unknown $(\mathrm{Z}=3.167, \mathrm{P}=0.00154)$ risk behaviours were each reported more in the 60 years and older age group with statistical significance at 10\%, 10\% and $70 \%$, respectively, compared with $0 \%, 0 \%$ and $21 \%$ in the 20- to 29-year-old age group, respectively.

Some general trends were noted. Non-IDU was reported more in the younger age groups and this seemed to decline with increasing age groups. However, IDU was reported at a level that did not differ greatly between age groups. Some of 
TABLE 6

Risk behaviours of interviewed acute and likely acute cases of hepatitis B, categorized using a mutually exclusive risk behaviour scheme and summarized by age group, reported by sites involved in the surveillance over the 1999 to 2002 study period

\begin{tabular}{|c|c|c|c|c|c|}
\hline \multirow[b]{2}{*}{ Risk factor } & \multicolumn{5}{|c|}{ Acute and likely acute hepatitis B } \\
\hline & $\begin{array}{l}10 \text { to } 19 \text { years } \\
\text { of age ( } n \text { [\%]) }\end{array}$ & $\begin{array}{l}20 \text { to } 29 \text { years } \\
\text { of age (n }[\%] \text { ) }\end{array}$ & $\begin{array}{l}30 \text { to } 39 \text { years } \\
\text { of age (n [\%]) }\end{array}$ & $\begin{array}{l}40 \text { to } 59 \text { years } \\
\text { of age (n [\%]) }\end{array}$ & $\begin{array}{l}60 \text { years of } \\
\text { age and older } \\
\text { (n [\%]) }\end{array}$ \\
\hline Noninjection drug use & $2(16.7)$ & $6(10.5)$ & $8(8.9)$ & $2(2.7)$ & $0(0)$ \\
\hline Blood transfusion & $0(0)$ & $0(0)$ & $0(0)$ & $0(0)$ & $1(10.0)$ \\
\hline Receipt of blood product & $0(0)$ & $0(0)$ & $0(0)$ & $1(1.3)$ & $1(10.0)$ \\
\hline Male homosexual activity & $0(0)$ & $4(7.0)$ & $15(16.7)$ & $8(10.7)$ & $0(0)$ \\
\hline Sexual contact with an HBV carrier & $0(0)$ & $9(15.8)$ & $6(6.7)$ & $2(2.7)$ & $0(0)$ \\
\hline Tattooing & $0(0)$ & $0(0)$ & $0(0)$ & $0(0)$ & $0(0)$ \\
\hline Body piercing & $0(0)$ & $0(0)$ & $0(0)$ & $0(0)$ & $0(0)$ \\
\hline Acupuncture & $0(0)$ & $0(0)$ & $1(1.1)$ & $4(5.3)$ & $0(0)$ \\
\hline Hospitalization & $1(8.3)$ & $1(1.8)$ & $2(2.2)$ & $3(4.0)$ & $0(0)$ \\
\hline Surgery & $0(0)$ & $0(0)$ & $0(0)$ & $2(2.7)$ & $0(0)$ \\
\hline Tissue/organ transplant recipient & $0(0)$ & $0(0)$ & $0(0)$ & $0(0.0)$ & $0(0)$ \\
\hline Dental visit & $0(0)$ & $1(1.8)$ & $3(3.3)$ & $4(5.3)$ & $0(0)$ \\
\hline Incarceration & $0(0)$ & $0(0)$ & $0(0)$ & $0(0)$ & $0(0)$ \\
\hline Unknown & $3(25.0)$ & $12(21.1)$ & $18(20.0)$ & $19(25.3)$ & $7(70.0)$ \\
\hline Interviewed & $12(70.6)$ & $57(58.2)$ & $90(68.2)$ & $75(67.0)$ & $10(58.8)$ \\
\hline Not interviewed & $5(29.4)$ & $41(41.8)$ & $42(31.8)$ & $37(33.0)$ & $7(41.2)$ \\
\hline Total & 17 & 98 & 132 & 112 & 17 \\
\hline
\end{tabular}

HBV Hepatitis B virus

the reported sex-associated risk behaviours had peaks with different age groups. Two or more heterosexual partners was reported as a risk behaviour more often with the youngest age group (ie, 10 to 19 years of age) and not reported at all with the oldest age group (ie, at least 60 years of age). Male homosexual activity tended to be reported more with the middle age groups, particularly the 30- to 59-year-old age group, while sexual contact with an HBV carrier was reported more with the 20- to 29-year-old age group than with the other age groups.

\section{DISCUSSION}

At its peak coverage, this surveillance project represented $28.6 \%$ of the Canadian population. The collected data came from three different year cohorts, which included a cohort that over-represented the central part of Canada and a cohort that contained a mix of east and west coast participants. Because there was little difference in incidence rates between the cohorts, it is likely that the rates are somewhat generalizable to all of Canada. However, there were some gaps in the surveillance coverage, and these included the absence of participants from Quebec, northern communities and Canada's largest city, Toronto.

The case definitions relied on the identification of symptomatic and laboratory-confirmed acute cases, as well as those determined to be likely acute based on a positive IgM anti$\mathrm{HBc}$ test only. This definition was partially weighted toward capturing incident clinical cases, and it has been indicated that up to $50 \%$ of adults and $90 \%$ of children may be asymptomatic in incident cases (12). Based on this, it is possible that the estimated incidence rates are actually as high as twice the rates that have been identified. From 1999 to 2002, an acute HBV infection rate of 1.93 per 100,000 person-years was assessed for the surveillance region. The rates were observed to decrease over the surveillance period, and rates were estimated to be 2.69 times higher in men when effects due to year and age were controlled. The incidence rates were highest with individuals in the 30- to 39-year-old age group and this was closely followed by individuals in the 20- to 29-year-old age group. With respect to sex and age, these observations were similar to those previously reported over a surveillance period of late 1998 to 1999 in Canada (8). With only four years analyzed and a limited variable set collected, it is not possible to hypothesize whether various interventions, such as past vaccination or health promotion programs, had an impact on the incidence rates. Past vaccination programs have targeted high-risk groups, and since the early 1990s, a school-based universal hepatitis $B$ vaccination program has been implemented for preadolescents in all provinces and territories (13); however, assessment of such interventions would require an additional set of variables to be collected over a period that included the preintervention period.

Non-Canadian-born individuals represented $22.6 \%$ of the acute and likely acute cases, Canadian-born individuals represented $55.9 \%$, and $21.5 \%$ were of unknown birth origin. 
These numbers are in contrast with 2001 census numbers, which reported $18.4 \%$ of the population as immigrants (14), suggesting a somewhat higher rate of acute and likely acute cases in the immigrant population. Within the acute and likely acute cases who were identified as being born in Canada, $11.3 \%$ were indicated to be Aboriginals, while $88.7 \%$ were indicated as non-Aboriginals; within those who reported their birthplace as Canada or unknown, these numbers changed to $8.5 \%$ and $91.5 \%$ for Aboriginal and nonAboriginal identification, respectively. According to the 2001 census, Aboriginal Canadian-born individuals account for approximately $3.3 \%$ of the population (15). This also indicates an over-representation of Aboriginals among the acute and likely acute cases.

Looking at risk factor comparisons, there were few differences in the characteristics of interviewed versus noninterviewed individuals. This indicates that there was little bias with respect to the responders and perhaps good generalizability of information obtained from the acute and likely acute cases. Using the mutually exclusive categorization of risk behaviours, IDU was the most reported risk behaviour at $19.1 \%$ and this was followed closely by sex-associated risk behaviours. However, there was a large proportion, $24 \%$, who indicated none of the known risk behaviours. This compares with the results from previous studies, which indicate that the predominantly known risk factors associated with hepatitis $B$ transmission in Canada are sexual contact and IDU when these behaviours involve contact with an infected individual's blood and/or body fluids $(1,4,8,9)$. There were some minor differences found between men and women. Among the risk behaviours reported during the past six months, the female cases reported a higher proportion of heterosexual activity with two or more partners than did men and, as would be expected, only men had the risk behaviour of male homosexual activity.

\section{REFERENCES}

1. Tepper ML, Gully PR. Hepatitis B. CMAJ 1997;156:1033-4.

2. Shaffer E, Wong F, King S, et al. The Management of Viral

Hepatitis: Proceedings of a consensus conference held in Montreal, Quebec in March 1999. <http://www.phac-aspc.gc.ca/publicat/ casl-acef $>$ (Version current at September 16, 2005).

3. Minuk GY, Zhang M, Wong S, et al. Viral hepatitis in a Canadian First Nations community. Can J Gastroenterol 2003;17:593-6.

4. Tepper ML, Gully PR. Lovers and livers: Hepatitis B as an STD. Can J Hum Sex 1997;6:135-42.

5. Scott RM, Snitbhan R, Bancroft WH, Alter HJ, Tingpalapong M. Experimental transmission of hepatitis B virus by semen and saliva. J Infect Dis 1980;142:67-71.

6. Roumeliotou-Karayannis A, Papaevangelou G, Tassopoulos N, Richardson SC, Krugman S. Post-exposure active immunoprophylaxis of spouses of acute viral hepatitis B patients. Vaccine 1985;3:31-4.

7. Health Canada. Routine Practices and Additional Precautions for Preventing the Transmission of Infection in Health Care. Can Commun Dis Rep 1999;25(Suppl 4):1-55.

8. Zou S, Zhang J, Tepper ML, et al. Enhanced surveillance of acute
The risk behaviours reported by interviewed cases also differed slightly by age group. Non-IDU was reported more in the younger age groups and this seemed to decline with increasing age groups. However, IDU was reported at a level that did not differ greatly between age groups. Some of the reported sexassociated risk behaviours had peaks with different age groups. Two or more heterosexual partners was reported as a risk behaviour more with the youngest age group and was not reported at all with the oldest age group. Male homosexual activity tended to be reported more with the middle age groups, particularly the 30- to 59-year-old age group, while sexual contact with an HBV carrier was reported more with the 20- to 29-year-old age group than with the other age groups.

There were some weaknesses in the current surveillance project. For individuals not interviewed on risk behaviours, the inability to interview may be directly related to their risk behaviour. For example, injection drug users and individuals involved in more risky sexual behaviours may be less easily contacted for follow-up once they leave their place of treatment. There may also be some recall bias in the individuals being interviewed because cases were asked about their actions over the previous six months. Currently unknown risk behaviours would have been captured in the unknown category. The ethnicity variable was only introduced in April 1999 and this impacted the number of missing responders to that variable in 1999.

As with most surveillance projects, the data collection from the current project was largely for the purpose of health intelligence. Such data collection is generally not as rigorous as would be expected from a more controlled health study. However, useful information can and has been collected that can support the development of evidence-based prevention and control programs, evaluate the effectiveness of preventive strategies and public health responses, and support the identification of at-risk populations for targeted research and intervention.

hepatitis B and C in four health regions in Canada, 1998 to 1999. Can J Infect Dis 2001;12:357-63.

9. Zhang J, Zou S, Giulvi A. Hepatitis B in Canada. Can Commun Dis Rep 2001;27(Suppl 3):10-2.

10. Public health agency of Canada. Notifiable diseases on-line. $<$ http://dsol-smed.phac-aspc.gc.ca/dsol-smed/ndis/index_e.html> (Version current at September 30, 2005).

11. SAS/STAT User's Guide, version 7-1. SAS Institute Inc, 1999.

12. Health Canada. Canadian Immunization Guide, 6th edn. $<$ www.phac-aspc.gc.ca/publicat/cig-gci/pdf/cdn_immuniz guide-2002-6.pdf > (Version current at September 16, 2005).

13. National Advisory Committee on Immunization. Canadian national immunization report: Program update. Paediatr Child Health 1999;4(Suppl C):30C-33C.

14. Census of population. Immigrant population by place of birth and period of immigration. Otttawa: Statistics Canada, 2003.

15. Statistics Canada. Aboriginal Peoples of Canada: Highlight Tables, 2001 Census. Catalogue number 97F0024XIE2001007. $<$ http://www.statcan.ca:8096/bsolc/english/bsolc?catno= 97F0024X2001007> (Version current at September 16, 2005). 


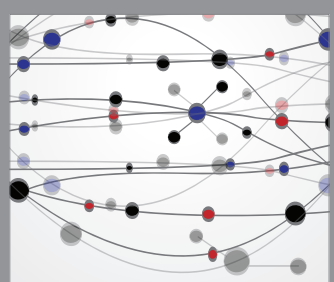

The Scientific World Journal
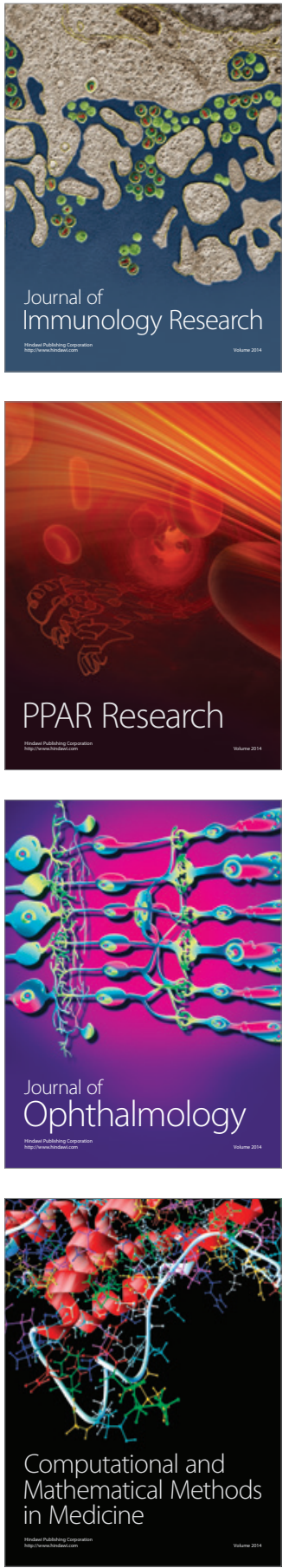

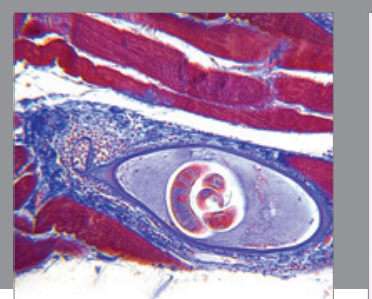

Gastroenterology Research and Practice

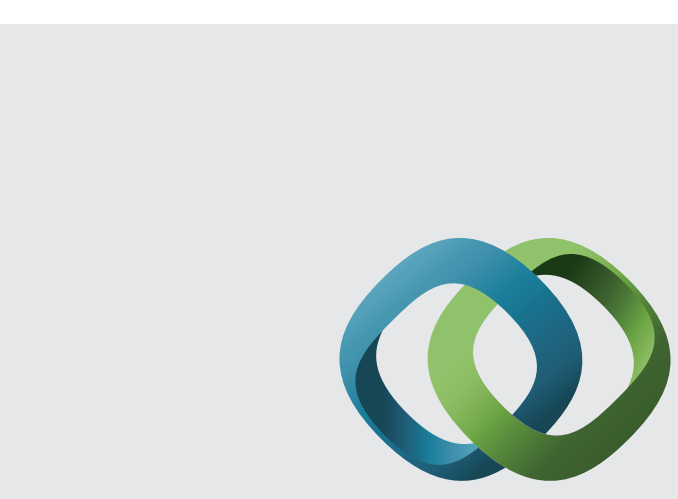

\section{Hindawi}

Submit your manuscripts at

http://www.hindawi.com
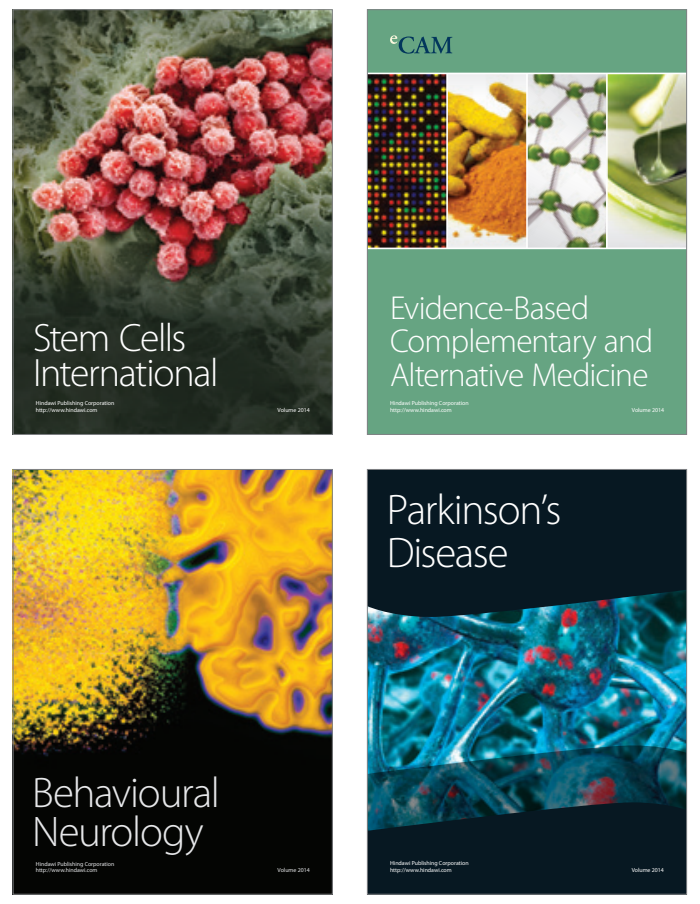
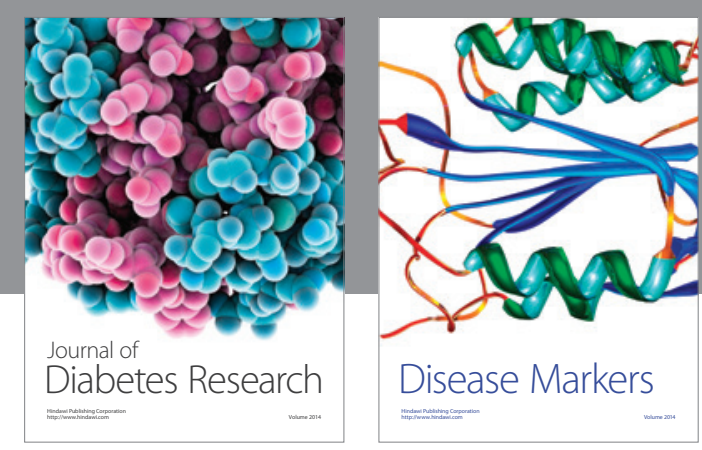

Disease Markers
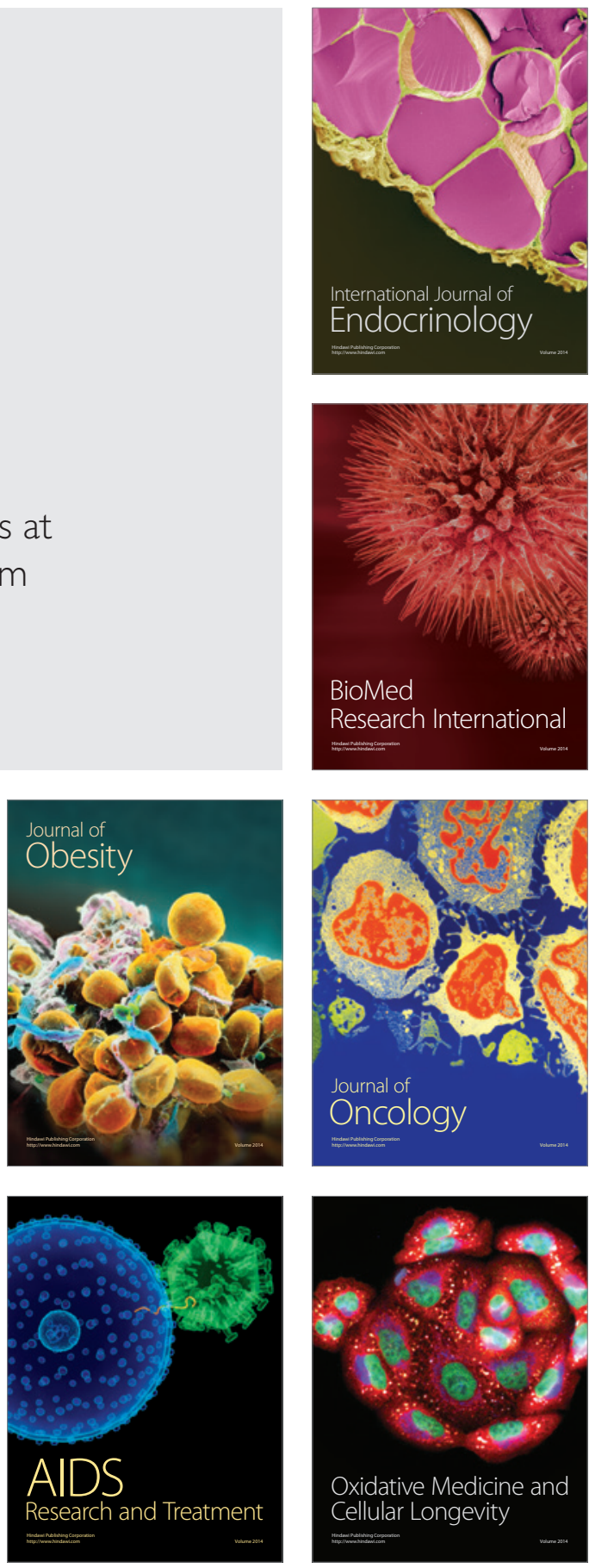